The Canadian Journal of Higher Education, Vol. XXV-1, 1995

La revue canadienne d'enseignement supérieur, Vol. XXV-1, 1995

\title{
The Systematic Design and Implementation of a Training Program for Teaching Assistants
}

\section{ALENOUSH SAROYAN* \& CHERYL AMUNDSEN*}

\begin{abstract}
An increase has recently occurred in the number of programs which formally prepare teaching assistants (TAs) for their designated teaching responsibilities. These programs may also be seen as an investment in preparing the future professorate for their teaching roles. This paper describes how a program for the training of teaching assistants was conceptualized and implemented at McGill, a large research-oriented Canadian university. A review of the relevant literature is followed by a detailed description of the systematic approach to program development involving needs assessment, planning and implementation, and evaluation. The relationship between various levels of the University and the way in which these relationships have strengthened the TA training program are highlighted.
\end{abstract}

\section{Résumé}

Récemment, il y a eu une augmentation dans le nombre de programmes qui formellement préparent les chargés de cours (teaching assistants) pour les responsabilités pédagogiques qui leur sont désignées. Il a été suggéré que ces programmes peuvent être considérés comme un investissement pour la formation future des professeurs dans leur rôle d'enseignant. Cet exposé décrit la conception et l'application d'un programme de formation pour chargés de cours à Université McGill, une grand université canadienne, reconnue pour son orientation en recherche. Une critique de la littérature pertinente sera suivie

* McGill University 
d'une description détaillée des étapes systématiques du développement du programme, incluant la détermination des besoins, la planification et l'application ainsi que l'évaluation. Aussi, la relation entre les différents niveaux de l'Université et la façon dans laquelle ces relations ont amélioré le programme de formation pour chargés de cours seront soulignées.

This paper describes how a program for the training of teaching assistants (TAs) was conceptualized and implemented at a large, research-oriented Canadian university. The rationale behind the paper is to provide those interested in implementing similar programs with a detailed view of a systematic approach taken toward TA training. The paper has three major sections. First, we provide a review of the literature on the training of teaching assistants focusing on studies which delineate the roles and responsibilities of TAs and those which examine the effectiveness of TA training in North America. Next we describe the program we have implemented at McGill for the training of TAs, emphasizing its evolution. Finally, we discuss a series of objective and subjective measures which we have used to assess this program and offer reasons as to why we feel it has succeeded in realizing certain goals and in gaining the interest and the support of the University administration. We end the paper by highlighting some ideas for future development in this area.

\section{The Literature on the Training of Teaching Assistants}

The training of teaching assistants can be considered to be both a short-term and a long-term investment for institutions of higher learning. In the short term, such training can have a direct impact on the quality of the course to which a TA is assigned. In the long-term, it can yield academics who have both training and expertise in their subject area and experience in general pedagogy and the pedagogy of that specific subject.

Despite previous assertions made in the literature regarding the value of TA training, it is only in the past few years that universities have actually put into place formal TA training programs (Wiemer, Svinicki, \& Bauer, 1989). Descriptions of such training programs, however, are still not readily found in the published literature. Several reasons can be associated with this apparent increase of interest in TA training. One reason has to do with the accumulated empirical evidence which suggests that TA training does have a positive, though limited impact on both TAs and the students they interact with. For instance, Carrol (1980) reported a positive change in the specific teaching behaviors targeted by training programs, and an attitudinal change in the way TAs felt towards immediate tasks such as developing behavioral objectives and 
criterion referenced tests. Improved student attitudes, course grades, and course evaluation ratings were also noted, although Carrol (1980) was unable to firmly establish the correlation between TA training and improvement in these areas. Lawrenz, Heller, Keith, and Heller (1992) reported results regarding training designed specifically to provide TAs with certain techniques in leading cooperative problem-solving groups. This program was implemented for one year, was evaluated and revised after the first year, and was reoffered and evaluated at the end of the second year. The comparative results indicated that the trained TAs were better able to facilitate problem-solving in their groups, and were more goal-oriented and confident in their teaching, while the students they led were more satisfied and appeared to be more attentive. In other studies, indirect interventions also produced improved ratings. For example, when TAs were given specific feedback based on their ratings in course evaluations, their ratings in subsequent terms improved (Abbott, Wulff, \& Szego, 1989). These and other findings suggest that it is possible to improve the teaching of TAs by means of certain kinds of direct and indirect interventions.

Another reason for increased interest with regards to the training of TAs may well be a reaction to current statistics on the aging professorate (The Chronicle of Higher Education, 1992; Nyquist, Abbott, \& Wulff, 1989) and the stated need to replenish this depleting force in the next decade (Angelo \& Cross, 1989). The long-term advantage of TA training has been promoted previously by Boehrer and Sarkisian (1985) as "apprenticeship for a lifelong career" rather than a means of supporting one's education during graduate student years. Schuster (1990) has argued that students are acculturated to the norms and values of academic life during their graduate student years and that teaching preparation, as well as other professional preparation, must be an integral part of this process, not separate from it. The pressing need for experienced and well-trained faculty members might well have changed the orientation of graduate schools which until now have almost exclusively aimed at developing scholarship and research-related skills. (In 1986 Schuster surveyed 82 administrators of graduate schools in the United States and they ranked "developing TAs as future faculty" as 12 th in importance among 24 activities and issues.)

Finally, a rise in the number of training programs for TAs may have been prompted by national surveys, forums, and inquiries and ensuing recommendations and policy statements. For instance, in the report generated by the Commission of Inquiry on Canadian University Education, one recommendation stated that "Every candidate for $\mathrm{PhD}$ should be offered training in modern teaching methods ... It should be obligatory that TAs receive such training before being called to teach university students" (Smith, 1991, p. 64). 
Influenced by the emerging evidence of the value of TA training, the estimated need for future academics, and calls from various levels to attend to the specific needs of this group, it appears that now there is a supportive atmosphere within many universities where creative ideas on TA training can be pursued.

\section{Profile of teaching assistants}

Interest in TA training has resulted in dedicating entire issues of publications to the topic (e.g., New Directions for Teaching and Learning: Teaching assistants training in the 1990s, vol. 39, 1989; The Chronicle of Higher Education, March 1992). Interest has also resulted in conferences and professional gatherings on this topic (e.g., The Fourth National Conference in the Training and Employment of Graduate Teaching Assistants held in Chicago in November 1993). As a result, we now have more demographic data on TAs and on the teaching responsibilities which they undertake. For instance, based on a survey of 26 Canadian institutions who responded fully or partially to a questionnaire entitled "TA Development Practices at Canadian Universities), $28 \%$ of the full-time and part-time graduate student population or $48 \%$ of the full-time enrollment hold TA positions (Piccinin, Farquharson, \& Mihu, 1993). We also know more about the role of TAs; the dual or transitory nature of this role due to the shift made from graduate student to teacher (Boehrer \& Sarkisian, 1985; Stanton \& Darling, 1989), and the range of responsibilities assumed by TAs. For instance, some TAs have complete responsibility for a course, others instruct discussion sections or laboratories, and yet others only mark assignments. In the Canadian survey (Piccinin, et al., 1993), data on the roles of TAs were presented under the two categories of Humanities/Social Sciences and Science/Engineering. In Humanities/Social Sciences, grading was proportionately the most engaging activity for TAs $(55 \%)$ while in Science/Engineering, laboratory instruction was by far the most common activity (59\%). (See Table 1.)

The role of TAs has also been described from a different perspective. Comments generated by a group of freshmen who attended a TA retreat described TAs as promoters of interactive learning and coaching in higher thinking skills. These students found that they were better able to integrate course content as a result of their interactions with TAs assigned to their courses (Andrews, 1985).

\section{TA Program Profiles}

Estimates from surveys across the U.S. suggest that TAs spend between $30 \%-50 \%$ of their time in direct contact with undergraduate students (The Chronicle of Higher Education, March 1992; Diamond \& Gray, 1987; Smock \& Menges, 1985). 
Table 1

Time allocation for TAs ${ }^{1}$

\begin{tabular}{lcc}
\hline & $\begin{array}{c}\text { Humanties/ } \\
\text { Social Sciences }\end{array}$ & $\begin{array}{c}\text { Science/ } \\
\text { Engineering }\end{array}$ \\
\hline Grading & $55 \%$ & $29 \%$ \\
Leading discussions & $35 \%$ & $5 \%$ \\
Lab instruction & $2 \%$ & $59 \%$ \\
Other & $7 \%$ & $7 \%$
\end{tabular}

\footnotetext{
${ }^{1}$ From: Piccinin, S., Farquharson, A., \& Mihu, E. (1993). Teaching Assistants in Canadian universities: An unknown resource. The Canadian Journal of Higher Education, 23(2), 104-117
}

Of course, the amount of face-to-face contact will vary depending on the responsibility given to the TA. During this interactive period, TAs engage in activities which require preparation beyond what normal academic programs offer. From what can be gleaned from the existing sparse literature, typically, departments or faculties plan and implement their own TA-training programs (Smock \& Menges, 1985; Weimer, et al., 1989) and only the most elaborate ones draw on resources which are external to departments. In some universities, as is the case at McGill, all faculty development programs, including those targeted for TAs, are offered through a centre which promotes and supports university teaching and learning and which operates as a unit under a senior university administrator, the Vice-Principal (Academic). In other institutions, such as at Syracuse, TA development activities are coordinated through the office of the Dean of Graduate Studies.

To train TAs both formal and informal apprenticeship experiences are deemed suitable. Some programs rely on printed materials such as TA Handbooks. Others offer courses and programs designed specifically for the pedagogical training of TAs (Write, 1989). Descriptions of specific programs indicate that some programs simply give information (e.g., information on university policy and issues such as sexual harassment and gender policy; Weimer, et al., 1989) while others are more applied and provide an opportunity for participants to practice specific skills such as coaching and clinical consulting (Angelo \& Cross, 1989).

While the most commonly stated purpose of TA training programs is to provide TAs with sufficient pedagogical knowledge to attend to their responsibilities 
(Carrol, 1980), many programs also consciously create suitable environments for TA networking and role clarification. It has been suggested that TA training programs need to specifically promote skills such as developing social support systems, obtaining information, adjusting to rules and policies, and generating new ideas for teaching and research (Stanton \& Darling, 1989).

The assessment of TA training programs can be as varied as the programs themselves. The most common method of assessment is opinion data, gathered immediately after a program has been implemented. To this end, evaluation forms filled out by the TAs who participate in the program/workshop are the major source of data. While such data might indicate the degree of like and dislike of particular activities or change at a cognitive level, they do not indicate any real change in TAs' teaching behaviour. Smock and Menges (1985) have suggested a set of criteria which in their view, extends the evaluation beyond the context of the workshop and can be systematically applied to assess "how well the university meets its obligation to help all [stakeholders]". Their criteria include accessibility, perceived usefulness, documented impact, feasibility, and compatibility with the university's philosophy and image.

In summary, the training of teaching assistants has gained momentum in North American universities partly because it fulfills the immediate need of having qualified TAs in place and partly because universities are taking leadership in the training of the future professorate. Details of programs which aim specifically toward the training of teaching assistants are sparse in the published literature even though there is ample evidence that they do exist. From what can be gleaned from this literature in Canada, nearly half of the full-time graduate students hold TA fellowships and in this position engage in a range of activities. These activities are quite complex and require specific skills which are not developed through normal course-work.

\section{Development of the McGill TA Training Program}

The teaching improvement activities at McGill University are coordinated through the Centre for University Teaching and Learning, a unit which reports to the Vice-Principal (Academic) and which is mandated to promote good teaching as well as research into higher education. At McGill, teaching is defined broadly and thus includes any form of instruction done by faculty members and by TAs, graduate student supervision, program development, and evaluation.

The Centre for University Teaching and Learning began its systematic approach toward the training of TAs by conducting a literature review on the topic. The next step was a needs assessment carried out to establish the extent of 
TAs' roles and responsibilities within each faculty. Subsequently, a universitywide TA orientation was planned, implemented, and evaluated. Data from various evaluation measures were used to make modifications to the program components. These steps are described in the following sections.

\section{Needs Assessment}

In order to gather descriptive data concerning the numbers and distribution of TAs at McGill, their assigned tasks, and departmental efforts to prepare them, a questionnaire was designed and pilot-tested at three administrative levels (one department head, one associate dean, and one graduate program director). After the necessary revisions, the questionnaire was mailed to 58 department chairs in January 1991. The selected information presented here is from findings based on an $82 \%$ response rate. (For a detailed account see Saroyan \& Amundsen, 1992.)

The total undergraduate student population of McGill in 1991 was reported at 22,413 and the graduate student population at 6838 (including part time, visiting, and special students). Thus TAs comprised $.8 \%(\mathrm{n}=189)$ and $8.5 \%$ ( $n=588$ ) of these groups, respectively. (See Table 2 for breakdown of numbers by faculty.) In the 1990-91 academic year when the survey was carried out, only a small proportion of the currently employed TAs were reported as having no previous experience as TAs. This situation was judged to be similar to previous years by $76 \%$ of the department chairs.

The survey indicated that the responsibilities of the TAs varied within and across faculties. By far, the major responsibility was marking assignments and exams. Other responsibilities included conducting tutorials/small group discussions and laboratory sessions, and individual consultations. In the three faculties which had the highest number of teaching assistants - Science, Engineering, and Arts - marking, conducting tutorials, conducting laboratory sessions, and individual student consultations comprised the four major activities. (See Table 3 for a detailed breakdown of responsibilities.) Apparently all faculties expected their TAs to engage in marking. All TAs in Engineering, Music, and Religious Studies were assigned tutorial responsibilities in addition to marking, presumably because these faculties have large classes or the subjects they teach require attention on a personal basis. Faculties which offer courses that have laboratory components used TAs primarily as lab demonstrators and interestingly, in the Faculty of Music, all the TAs were systematically given a range of responsibilities in order to broaden their teaching experience.

At the time of the survey, the amount of formal preparation that TAs received at McGill was limited. Only one third of the departments reported having organized activities to prepare TAs. These included workshops, weekly 
Table 2

Number of TAs in faculties which responded to the survey ${ }^{1}$

\begin{tabular}{|c|c|c|c|c|}
\hline Faculty & $\begin{array}{c}\text { Number } \\
\text { of TAs }\end{array}$ & $\begin{array}{l}\% \text { of } \\
\mathrm{TAs}^{2}\end{array}$ & $\begin{array}{c}\text { Number of } \\
\text { Graduate TAs }\end{array}$ & $\begin{array}{c}\text { Number of } \\
\text { Undergraduate TAs } \\
\end{array}$ \\
\hline Science & 353 & 45.43 & 251 & 102 \\
\hline Arts & 150 & 19.30 & 105 & 45 \\
\hline Engineering & 141 & 18.14 & 115 & 26 \\
\hline \multicolumn{5}{|l|}{ Agricultural \& } \\
\hline Environmental Sciences & 48 & 6.18 & 44 & 4 \\
\hline Education & 35 & 4.50 & 23 & 12 \\
\hline Music & 25 & 3.21 & 25 & 0 \\
\hline Medicine & 20 & 2.51 & 20 & 0 \\
\hline Religious Studies & 5 & 0.64 & 5 & 0 \\
\hline
\end{tabular}

meetings with instructors and experienced TAs, or short orientation sessions. The performance of TAs was evaluated in several ways. Most departments included specific questions related to TA performance in the regular course evaluation forms which are administered every term in all courses. Some were evaluated by the responsible professor or by means of informal reports from students. Other methods included statements about the TA's understanding of course materials, previous experience as a TA, and current academic standing.

One of the most interesting findings of this survey was the way in which effective TAs were characterized by departments. Respondents referred to such qualities as knowledge of the subject matter, effective communication skills, commitment, positive attitude, and pleasant personality. With the exception of the last two, all variables are identical to the course evaluation forms for professors. Attitude and personality traits, however, are not deemed as relevant when judging the quality of teaching as they have shown little relationship to student ratings (Feldman, 1986).

In response to a question regarding the kind of support needed from the University (specifically from the Centre for University Teaching and Learning) for improving TA training, a considerable number of departments requested assistance in developing evaluation methods. Others suggested help in conducting 
Table 3

TA activities and the percentage of TAs assigned to these activites by faculty' $\underline{(N=777)}$

\begin{tabular}{|c|c|c|c|c|c|c|c|c|c|}
\hline \multirow[t]{2}{*}{ Activity } & \multicolumn{9}{|c|}{$\%$ by Faculty } \\
\hline & Ag. \& ES. & Arts & Educ. & Eng. & Med. & Mus. & Rel .St. & Sci. & Total \\
\hline Marking & 100 & 75 & 100 & 100 & 100 & 100 & 100 & 90 & 90.63 \\
\hline Conducting labs & 100 & 25 & 33 & 100 & 0 & 100 & 0 & 90 & 74.74 \\
\hline Tutorials & 20 & 66 & 33 & 100 & 66 & 100 & 100 & 70 & 70.97 \\
\hline Ind. consultations & 40 & 66 & 100 & 50 & 33 & 100 & 100 & 40 & 51.67 \\
\hline Prep. materials & 40 & 41 & 33 & 25 & 0 & 100 & 100 & 30 & 33.90 \\
\hline Tchg. few lectures & 60 & 33 & 33 & 25 & 33 & 100 & 0 & 20 & 29.25 \\
\hline Tchg. one session & 20 & 41 & 0 & 25 & 33 & 100 & 100 & 10 & 22.94 \\
\hline Assisting professors & 0 & 8 & 66 & 25 & 33 & 100 & 0 & 20 & 22.21 \\
\hline
\end{tabular}

"field supervision", "one day or half-day workshops", "workshop on discussion techniques", or "simply providing a listing of available services".

Before conducting the survey, the possible implications of a universitywide TA training program in the context of the decentralized structure of McGill were examined. In this context departments are formally responsible for supporting and evaluating teaching including any teaching functions carried out by teaching assistants. Moreover, delineating the rights and responsibilities of teaching assistants rests at the department level and for that reason, the survey was aimed at departmental administrators. The overall findings confirmed that the responsibilities of teaching assistants and the activities used to prepare them varied from one department to the next. It also became evident that a coordinated effort with departments would be necessary to effectively meet the expressed needs and that even though a university-wide training program completely organized by the Centre for University Teaching and Learning was appealing, such activities would be of only limited value to departments with specific needs.

\section{Planning and Implementation}

The results of the survey described above, review of the literature, and experience with other teaching development initiatives directed the planning of the 
TA program. Departments comprise the focal point in all activities related to TAs; however, the interest and the support of senior administration is also needed because to a certain extent, departments look to faculty and university levels for the approval of new initiatives. Based on this premise, four program components were initially implemented. The desired impact of each can be traced in Figure 1.

Academic Policy and Planning Subcommittee on University Teaching and Learning (SCUTL). We were able to draw support from the University's Academic Policy and Planning Subcommittee concerned with teaching and learning (SCUTL). This committee which is chaired by the Vice Principal (Academic), consists of one representative from each faculty and two members from the Centre for University Teaching and Learning. The mandate of the committee is to study the University's needs for the improvement of teaching and learning and to make recommendations on how to meet these needs. Input was solicited from this committee to refine ideas about TA training and its members became direct top-level link with faculties and with the central administration.

Department network. To gather support at the departmental level, departments were requested to appoint one faculty member to coordinate TA-related activities. The purpose of developing a network at this level was to provide a reliable way of communicating with departments at the grassroots level as well as to ensure that particular needs, as expressed in the survey, would be addressed in any university-wide training program that the CUTL would organize and offer. This also served as a channel through which the activities of some departments concerning TAs were publicized to other departments. For instance, when one particular department developed a document in which the roles and responsibilities of their TAs were explicitly described, it was forwarded to the Centre for University Teaching and Learning and in turn circulated to other departments through the network.

A cross-disciplinary course on teaching and learning. The McGill Centre for University Teaching and Learning has been offering a course on university teaching for the last several years. As the idea of a more comprehensive TA program developed, this course was revised to serve the current needs of TAs in all disciplines specifically to prepare those who are headed towards academic careers. Thus, two major changes were implemented. First, the course was moved to a central location to accommodate easy access and its existence was advertised every term in all departments. Second, its content and delivery were revised to reflect cognitive theories and current thinking about teaching and to provide a context which would accommodate interdisciplinary participation. 
Figure 1

Approach to TA Training

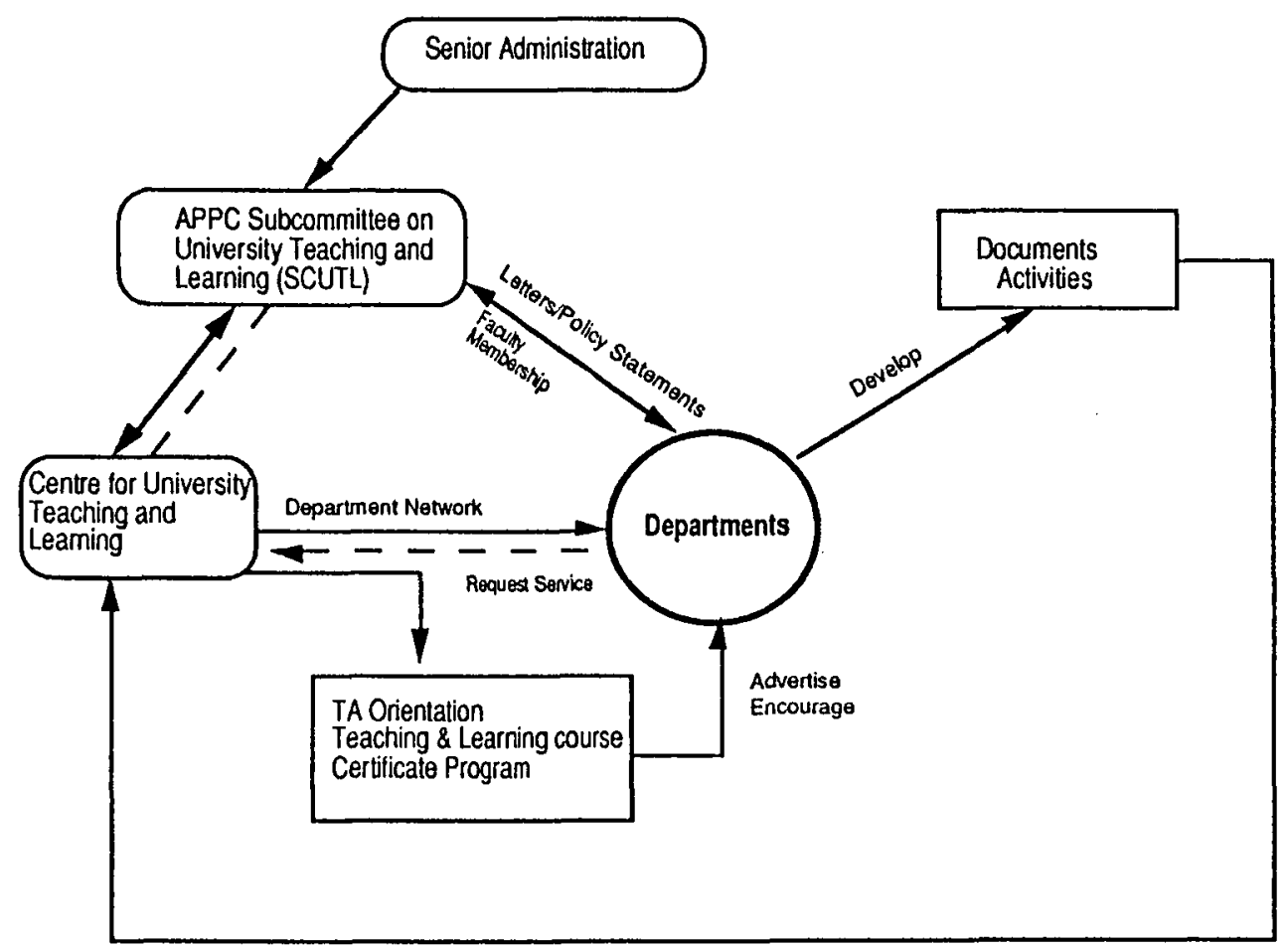


A university-wide TA orientation. The survey findings suggested that very few departments had formal programs for preparing their TAs. The idea of a university-wide TA orientation evolved from the success of an existing orientation which the CUTL offers annually for new faculty members. Its purpose was to provide TAs with a formal review of their roles and responsibilities, to acquaint them with the resources and support services available to them and to the students they instruct, and to give them the opportunity to discuss their roles with other more experienced TAs. The first orientation was offered in 1992 for a half day and was attended by approximately one-third of the TA population $(n=230)$. The departmental network described above was used to solicit the names of experienced and particularly effective TAs. These individuals were invited to contribute to the orientation and were subsequently trained for this purpose. The orientation format consisted of panel discussions, small group discussions, and short, large-group presentations. The discussion panels were led by experienced TAs and focused on the rights and responsibilities of TAs and effective communication with professors and students. The small groups were also led by experienced TAs and were on the various teaching roles of TAs (lab instructor, marker, discussion leader, and primary course instructor). Brief presentations on related topics such as sexual harassment and plagiarism were also included. With a few minor changes, the orientation was offered for a second year. This time participation dropped $(n=100)$. Some insight about this situation was provided through the comments about timing and advertising.

For a better turnout, try holding the orientation at another time than Friday afternoon.

I guess you should not rely on each individual department to advertise this. Just a series of posters on boards would do a lot of good.

Also, the importance of clear communication with regards to the focus of the orientation and the intended audience (i.e., experienced or inexperienced TAs) became quite clear. From the circulated information, TAs who had participated the previous year could not determine whether they would gain anything new by taking part in a second orientation. These issues have been carefully considered in the planning of the forthcoming orientation which will be offered in a completely different format. There will be a conference style program with sessions scheduled during lunch hours (12:00-1:30) and late afternoons (4:00-5:30) during an entire week. This format will enable the organizers to offer sessions of interest to various groups and in smaller and more interactive set-ups. 


\section{Evaluation of Program Components}

Formal evaluation. To evaluate the success of the four components of our program, we have used most of the criteria recommended by Smock and Menges (1985). For perceived usefulness, formal evaluations and satisfaction ratings have been used for the course and the TA orientation programs.

\section{A. Cross-disciplinary course on teaching and learning in higher education:}

The course on university teaching and learning has been extremely well received. Throughout the past 5 years, formal course evaluations have shown a mean overall rating of 4.8 on a scale of $1-5$, where 1 is the lowest rating. Since evaluations are anonymous, it is not possible to ascertain effectiveness by faculty; however, solicited and unsolicited student comments report the overall value of the course. The following selected comments are representative of those we receive every term:

Maybe in the near future, this course should be made compulsory for every university professor. There should be a continuation of this course. It is an excellent course.

The diversity of students' backgrounds contributed much in terms of educational techniques and perspective that could be applied to different courses.

This course presented me with one of the most valuable educational experiences I have ever had. Its stimulated my thinking to integrate various areas into a dynamic whole. I would highly recommend it to anyone who aspires to become a university teacher.

Another measure of the pertinence and value of this course has been the consistency in enrollment and wider representation from departments (Table 4). Since this course is offered in the Faculty of Education and is a core course in the Educational Psychology Graduate program, enrollment figures tend to favor this faculty; however, because the interdisciplinary nature of this course provides a unique dimension and because of the micro-teaching component which requires considerable individual time, as of September 1994, some changes will be put in place to have a more balanced representation. Changes consist of limiting enrollment to 15 students per term and limiting the number of students from the Faculty of Education to 6 per term.

Finally, each term, one or two students have proposed to teach the course they developed as the final assignment and have successfully done so. Examples are courses in Engineering Ethics, Space Law, and Lithography. In such cases, letters of appreciation forwarded to the individuals by program chairs/directors have been copied to the CUTL instructors. 
Table 4

Enrollment data in the course on University Teaching and Learning

\begin{tabular}{lccccccc}
\hline Faculties & W'91 & $\mathrm{F}^{`} 91$ & W'92 & $\mathrm{F}^{`} 92$ & W'93 & F’93 $^{\prime}$ & W'94 \\
\hline Arts & 1 & & & 2 & 2 & 1 & 4 \\
Education & 10 & 5 & 10 & 10 & 16 & 6 & 3 \\
Engineering & & & & & 1 & & 2 \\
Law & 1 & & 1 & 2 & 1 & & 2 \\
Medicine & 1 & 1 & & & & 1 & \\
$\begin{array}{l}\text { Music } \\
\text { Religious Studies }\end{array}$ & & & & & & 1 & \\
$\begin{array}{l}\text { School of } \\
\quad \text { Social Work }\end{array}$ & & 2 & & & & & \\
$\begin{array}{l}\text { Science } \\
\text { External }\end{array}$ & 13 & 8 & 14 & 16 & 20 & 9 & 12 \\
\hline Total & & & & & & & \\
\hline
\end{tabular}

B. University-wide TA orientation:

The results of the formal evaluation of the first TA Orientation indicated an overall mean satisfaction rating of 4.0. Small group discussion with experienced TAs received the highest individual mean rating (4.2). The following representative comments indicate the value of the orientation to participants.

Many important issues were addressed, and as a first time TA, I found this information extremely helpful and reassuring.

Well done. The issue of teaching at this level seems far too often neglected.

Overall, the workshop was very effective in addressing subjects that previously I had just "dealt with" on my own. Seeing so many others who had confronted the same issues and come up with innovative solutions was quite empowering and motivating for developing my teaching skills.

Thank you. I think that this kind of cross-faculty forum for TAs to network and discuss issues is very important. Let's do some more.

The results of this formal evaluation were compiled and a report was developed which was submitted to all SCUTL committee members and all department representatives. The report included recommendations for the steering 
committee (comprised of departmental representatives and experienced TAs) of the subsequent orientation workshop as well as for individual departments. Three of the recommendations which were implemented by the steering committee in the orientation offered the following year were:

1. An increased time for small group discussions with experienced TAs.

2. More extensive advertising of the workshop.

3. Inclusion of experienced TAs from all Faculties in the orientation.

In light of McGill's decentralized nature, these two additional recommendations were made to departments based on the direct request of workshop participants:

1. Departments should consider providing written guidelines concerning the employment of TAs and associated rights and responsibilities.

2. Departments should consider offering an orientation for new and returning TAs either independently or in conjunction with the university wide TA orientation.

Several departments have already initiated activities to address these concerns.

The second TA orientation yielded an overall mean rating of 4.1 and as in the previous year, small-group discussions was one of the activities evaluated most highly $(\bar{x}=4.2)$. Both the course and the orientation are university-wide programs which are advertised systematically through departmental networks. This meets the Smock and Menges (1985) criterion of accessibility.

Informal evaluation of programs. Involving university level committees and departments has been one way of ensuring that programs are compatible with and reflect the University's philosophy on teaching and learning and that they are feasible and can be implemented with current resources. This is further elaborated below.

\section{A. Academic Policy and Planning Subcommittee on University Teaching and Learning (SCUTL):}

The increase in the number of policy statements and guidelines related to TA activities which have been initiated by SCUTL is an indication of a university-wide interest and support for TA training. One such policy established the course on university teaching and learning free of charge to all doctoral students. Another involves the development and subsequent approval by the McGill Senate of criteria for cyclical review committees concerning the evaluation of teaching. Other indications of involvement have been: 
- A letter from Vice Principal, Academic (Chair of SCUTL) requesting department chairs to appoint one faculty member to coordinate and initiate activities related to TA preparation. This was the first step in developing the department network.

- Active participation of SCUTL committee members on the steering committee for the TA orientation and their influence on deciding the format of this orientation. The concept of a certificate in university teaching which is described later in this paper, has also been developed by this committee.

\section{B. Departmental network:}

In building a departmental network, progress has been slow but positive. Now, after two years, over $75 \%$ of the departments have complied in appointing a faculty member as a TA coordinator. Some of these individuals have been instrumental in gathering departmental support and in producing formal documents which stipulate the rights and responsibilities of TAs. Such documents, when compiled, are made available to the Centre for University Teaching and Learning, which in turn provides other departments with copies. In addition, some of network members have also been members of various committees related to the preparation of TAs and have led their departments in initiating department level orientations.

\section{Future Directions and Conclusions}

The success of the course on university teaching and learning, the TA orientation, the commitment of the University to the training of future academics, and the enthusiasm shown on the part of the University administration as well as graduate students have been instrumental in conceptualizing a fifteen-credit certificate program in university teaching. This program, which as yet has not been approved by Graduate Programs Committee, aims at providing graduate students who aspire towards academic positions with a solid training in pedagogy. The program consists of the following courses:

Teaching and Learning in Higher Education ( 3 credits)

Series of 10 seminars to be chosen from a menu of topics ( 3 credits)

Effective or Advanced Written Communication (3 credits)

Practicum I- TA Apprenticeship-supervised by Centre faculty (3 credits)

Practicum II-TA Apprenticeship-supervised by Departmental faculty ( 3 credits) 
In addition to the certificate program, an electronic discussion forum has been set up with the intent of promoting continuous dialogue on issues that are of interest and concern to TAs. These issues are either brought forward by individual TAs or are introduced as cases for discussion by the manager of the listserve who is a doctoral student associated with the Centre for University Teaching and Learning.

The systematic design of our TA training program has focused on gathering support and participation from administration, faculty, and TAs themselves. The involvement of central administration has yielded a number of significant outcomes one of which has been the revision of criteria concerning promotion and tenure where excellence in teaching is recognized. The central administration also submitted a proposal to a major Canadian bank based on the Centre for University Teaching and Learning annual reports. As a result, a substantial award has been granted to be used explicitly for teaching improvements projects. While the value of the support received from the central administration is acknowledged, we strongly believe that in our decentralized context, the focus of the efforts of a centre such as ours must be at the department level. The goal is that departments assume primary responsibility toward preparing teaching assistants while the Centre continues to retain the responsibility for implementing programs of general interest to TAs across the University. This is one of the ways to function effectively at a time when financial and personnel restrictions are constant threats to the quality of teaching in universities. It is also an effective way to document the long-term impact of the various TA training activities on the TAs when they actually teach, and on the students with whom they interact.

\section{References}

Abbott, R.D., Wulff, D.H., \& Szego, C.K. (1989). Review of research on TA training. In J.D. Nyquist, R.D. Abbott, \& D.H. Wulff (Eds.). Teaching assistants' training in the 1990s (pp. 111-124), New Directions for Teaching and Learning Series. San Francisco: Jossey-Bass, Inc., Publishers.

Andrews, J. D. (1985). Why TA training needs instructional innovation. In J.D. Andrews (Ed.), Strengthening the teaching assistant faculty (pp. 47-62), New Directions for Teaching and Learning Series. San Francisco: Jossey-Bass, Inc., Publishers.

Angelo, T., \& Cross, P. (1989). Classroom research for teaching assistants. In J.D. Nyquist, R.D. Abbott, \& D.H. Wulff (Eds.), New Directions for Teaching and Learning Series, Teaching assistants' training in the 1990s (pp. 99-110). San Francisco: Jossey-Bass, Inc., Publishers.

Boehrer, J., \& Sarkisian, E. (1985). The teaching assistants' point of view. In J. D.W. Andrews (Ed.), New Directions for Teaching and Learning Series, The teaching assistants' point of view (pp. 7-20). San Francisco: Jossey-Bass, Inc., Publishers. 
Carrol, G. (1980). Effects of training programs for university teaching assistants. Journal of Higher Education, 51 (2), 164-182.

Colleges expand efforts to help teaching assistants learn to teach. (1992, March 4). The Chronicle of Higher Education, pp. A17-A18.

Diamond, R.M., \& Gray, P. (1987). National study on teaching assistants. Syracuse, NY: Center for Instructional Development, Syracuse University.

Feldman, K. (1986). The perceived instructional effectiveness of college teachers as related to their personality and attitudinal characteristics: A review and synthesis. Research in Higher Education, 26, 227-298.

Lawrenz, F., Heller, P., Keith, R., \& Heller, K. (1992). Training the teaching assistant. Journal of College Science Teaching, 22(2), 106-109.

Nyquist, J.D., Abbott, R.D., \& Wulff, D.H. (1989). The challenge of TA training in the 1990s. In J.D. Nyquist, R.D. Abbott, \& D.H. Wulff (Eds.), New Directions for Teaching and Learning Series. Teaching assistants' training in the 1990s (pp. 7-14). San Francisco: Jossey-Bass, Inc., Publishers.

Piccinin, S., Farquharson, A., \& Mihu, E. (1993). Teaching assistants in Canadian universities: An unknown resource. The Canadian Journal of Higher Education, 23(2), 104-117.

Saroyan, A., \& Amundsen, C. (May, 1992). A survey of teaching assistants' roles and responsibilities. Paper presented at the Canadian Evaluation Society Conference in Ottawa, ON.

Schuster, J.H. (1990). Strengthening career preparation for prospective professors. In J.H. Schuster \& S.W. Wheeler (Eds.), Enhancing faculty careers: Strategies for development and renewal, (pp. 65-83). San Francisco: Jossey-Bass, Inc., Publishers.

Smith, S. (1991). Report of the Commission of Inquiry on Canadian University Education. Ottawa, ON: Association of Universities and Colleges of Canada.

Smock, R., \& Menges, R. (1985). Programs for TAs in the context of campus policies and priorities. In J.D.W. Andrews (Ed.), New Directions for Teaching and Learning Series, The teaching assistants' point of view (pp. 21-34). San Francisco: JosseyBass, Inc., Publishers.

Stanton, A., \& Darling, A. (1989). Socialization of teaching assistants. In J.D. Nyquist, R.D. Abbott, \& D.H. Wulff (Eds.), New Directions for Teaching and Learning Series, Teaching assistants' training in the 1990s (pp. 15-22). San Francisco: Jossey-Bass, Inc., Publishers.

Weimer, M., Svinicki, M., \& Bauer, G. (1989). Designing programs to prepare TAs to teach. In J.D. Nyquist, R.D. Abbott, \& D.H. Wulff (Eds.), New Directions for Teaching and Learning Series, Teaching assistants' training in the 1990s (pp. 5770). San Francisco: Jossey-Bass, Inc., Publishers.

Write, D. (1989). TA training resources. In J.D. Nyquist, R.D. Abbott, \& D.H. Wulff (Eds.), New Directions for Teaching and Learning Series, Teaching assistants' training in the 1990s (pp. 125-132). San Francisco: Jossey-Bass, Inc., Publishers. 